\title{
PRÁTICAS PEDAGÓGICAS: DIÁLOGO INTERTEXTUAL ENTRE LINGUAGENS CULTURAIS E O ENSINO DE HISTÓRIA E CULTURA AFRO-BRASILEIRA E INDÍGENA ${ }^{1}$
}

\author{
PEDAGOGICAL PRACTICES: INTERTEXTAL DIALOGUE BETWEEN CULTURAL \\ LANGUAGES AND THE TEACHING OF HISTORY AND AFRO-BRAZILIAN AND \\ INDIGENOUS CULTURE
}

\author{
Sueli do Nascimento \\ Doutoranda em Educação \\ Faculdade de Filosofia e Ciências - Unesp/Campus de Marília. \\ Marília, São Paulo - Brasil. \\ sueli.nascimento@unesp.br \\ Diogo da Silva Roiz \\ Doutor em História \\ Universidade Estadual de Mato Grosso do Sul - UEMS/Unidade de Paranaíba. \\ Paranaíba, Mato Grosso do Sul - Brasil. \\ diogosr@uems.br
}

Resumo: De acordo com Rüsen (2010), sentidos novos podem levar a novas representações no contexto histórico da experiência do passado, que requer novas técnicas. Esta pesquisa qualitativa foi realizada na cidade de Araçatuba/SP, com 49 acadêmicos dos cursos superiores em tecnologia. A escolha do campo de investigação e da população foi feita em razão da disciplina de História e Cultura Afro-Brasileira e Indígena, inserida pelas leis $n^{\circ} 10.639 / 03$ e $\mathrm{n}^{\circ} 11.645 / 08$. O instrumento aplicado pela professora baseia-se na perspectiva argumentativa da pesquisa-ação, envolvendo pesquisadora-professora e participantes-acadêmicos. Foram propostas duas indagações-argumentativas aos discentes: "Como observam a participação dos indígenas/negros na história do Brasil? Qual o significado das palavras índio/negro na história do Brasil". Analisaramse, sob a óptica da competência narrativa da consciência histórica, a consciência transitiva ingênua freireana e a consciência prévia rüseniana, as possíveis alterações a partir do saber histórico, intermediado por linguagens culturais (livros literários, músicas, filmes e documentários brasileiros) do século XVIII ao XXI. Os resultados demonstram que o alunado correspondeu às propostas, frisando a continuidade desse processo nesta e em outras instituições de nível superior.

Palavras-chave: consciência histórica; história e cultura afro-brasileira e indígena; educação reflexiva.

Abstract: According to Rüsen (2010), new senses can lead to new representations in the historical context of past experience, which requires new techniques. This qualitative research was carried out in the city of Araçatuba, SP, Brazil, with 49 university students from technology courses. The choice of the field of research and research population were made in connection with the subject "Afro-Brazilian and Indigenous History and Culture, introduced by laws 10.639/03 and 11.645/08. The instrument applied by the teacher is based on the argumentative perspective of action research, involving researcher-teacher and academicparticipants. Two argumentative questions were proposed to the students: -" How do you see the participation of indigenous $/$ black people in the history of Brazil? - What is the meaning of the words Indian / Negro in the history of Brazil? "We analyzed, from the perspective of the narrative competence of historical consciousness, the Freirean naive transitive consciousness and the previous Rüsenian consciousness, the possible alterations based on historical knowledge, which are intermediated by culture languages (literary books, music, films and Brazilian documentaries) from the 18th to the 21 st century. The results show that the students complied with the proposals, stressing the continuity of this process in this and other higher education institutions.

Keywords: historical consciousness; afro-brazilian and indigenous history and culture; reflective education.

\section{Para citar - (ABNT NBR 6023:2018)}

NASCIMENTO, Sueli do; ROIZ, Diogo da Silva. Práticas pedagógicas: diálogo intertextual entre linguagens culturais e o ensino de história e cultura afro-brasileira e indígena. Eccos - Revista Científica, São Paulo, n. 59, p. 1-18, e13920, out./dez. 2021. Disponível em: https://doi.org/10.5585/eccos.n59.13920.

\footnotetext{
${ }^{1}$ Uma primeira versão deste trabalho foi apresentada na $39^{a}$ Reunião Nacional da ANPEd Nacional.
} 


\section{Introdução}

[...] O agir humano é sempre determinado por significados e é intencional; o mesmo vale - mesmo se de outro modo para situações em que o homem é paciente. Ideias são os referenciais supremos que emprestam significado à ação e à paixão.

(RÜSEN, 2010b, p. 31)

Através desse agir, postulado e movido por ideias que ressignificam a paixão - entendida na acepção filosófica do termo -, pretende-se contribuir para a audaciosa ação do sujeito humano que, ao se relacionar intencionalmente com outros, transforma as carências de ordem temporal em motivações de interesse para o conhecimento histórico. Consequentemente, interpreta-se a primordialidade do passado - até então ensimesmada -, caracterizando-o como história, além de práxis da vida. Nesse contexto epistemológico, surge a inquietação: "Não aguento ser apenas um sujeito que abre portas, /que puxa válvulas, que olha o relógio, /que compra pão às 6 horas da tarde" (BARROS, 1996, p. 79)².

O poeta sul-mato-grossense propõe uma indagação reflexiva que vem ao encontro da proposta deste trabalho. Sob a perspectiva do sujeito e do mundo, e do porquê de uma ação intencional de "renovar o homem usando borboletas" entre sujeitos, na precisa busca de "ser Outros", ousa-se aliar este aspecto à objetividade de trilhar o caminho da formação da consciência histórica.

Neste sentido, pleiteia-se a luta e/ou a sobrevivência, nas palavras de Freire (2000), para enfrentar as turbulências diárias para executar humanamente seu papel transformador e a elas resistir. Tudo isso numa sala de aula, âmbito de enfrentamento das inúmeras mazelas da atual vida social, política e afetiva, assombrada pela ausência de reflexão, de um diálogo conciso e fluente sobre a análise conceitual e historiográfica. Os percalços diários são: superar a meritocracia, como também o que se impõe na empacotada matriz curricular, numa tentativa insistente de provocar o pensamento e a consciência histórica.

Assim, um processo interdependente de cinco fatores, extraídos do pensamento rüseniano (2010a, p. 35) e considerados de suma importância, circula entre métodos (regras da pesquisa empírica), formas (de apresentação), funções (de orientação existencial), interesses (carências de orientação no tempo) e ideias (perspectivas orientadoras da experiência do passado), ou seja, fatores que se fazem necessários numa aprendizagem significativa. E, em referência a regras indissociáveis do pensamento histórico, ainda sob o prisma de Rüsen (2010b,

\footnotetext{
${ }^{2}$ BARROS, Manoel. Retrato do artista quando coisa. Rio de Janeiro: Record, 1996.
} 
p. 37), "as funções da histografia", que "se referem ao interesse em conhecimento histórico", ponto a que a contemporaneidade do pensamento histórico se refere como "inquietação por mudança". Acredita-se, neste estudo, em mudanças a partir de novos interesses, capazes de modificar as "perspectivas orientadoras com respeito ao passado", levando a novas representações e a novas técnicas de pesquisa (RÜSEN, 2010b, p. 37).

Trata-se, nas palavras do mesmo autor, de um postfestum, de uma interação reconhecida com o passado, indispensável ao processo. Esse processo, intencionalmente proposto a acadêmicos/as dos cursos superiores de Tecnologia, surgiu por conta da disciplina inserida no ensino superior em virtude da Lei $\mathrm{n}^{\circ}$. 10.639, de 9 de janeiro de 2003, que alterava a Lei $\mathrm{n}^{\circ}$ 9.394, de 20 de dezembro de 1996, que estabelecia as diretrizes e bases da educação nacional, e pela Lei $\mathrm{n}^{\circ} 11.645 / 08$. Esse processo foi finalizado, em sua primeira etapa, numa determinada faculdade, em 2018.

$\mathrm{O}$ procedimento concluiu o primeiro percurso investigativo que impulsiona a priori certos questionamentos. Ora, se "nenhum saber histórico é amorfo" (RÜSEN, 2010a, p. 10), sob que formas ou funções se completa o saber histórico? Neste segmento da pesquisa, com base na tipologia de Jörn Rüsen ${ }^{3}$, discutem-se os conceitos de competência narrativa relativamente a aprendizagem histórica, pensamento e consciência histórica e premência de um diálogo intertextual, de acordo com uma nova técnica. Para tal itinerário, o repensar e o reconstruir os conteúdos empíricos, integrados à elaboração e à representatividade narrativa na continuidade temporal (passado, presente e futuro), demandam ousar na transformação da experiência em narrativa, num árduo trabalho pedagógico intencional de aprendizagem significativa segundo um modo específico de orientação. Orientação, em situações práticas da vida no presente, articuladas à conexão entre o passado e o presente, propondo perspectivas de futuro para a realidade em que se vive.

Instaurar subsídios para consolidar a historicidade empírica da realidade das sociedades e das culturas constitui também outro grande desafio. Maior ainda que o de simultaneamente dominar o método que ininterruptamente envolve o sujeito pensante, tornando-o agente a trilhar a aplicabilidade desta pesquisa participante e a dar tratamento qualitativo aos dados. $\mathrm{Na}$ expressão de Elie Wiesel (2005), conseguir o domínio "do passado, entendê-lo, explicá-lo, de modo a compreender o presente e planejar o futuro". Esta referência, extraída da introdução à edição brasileira da obra Teoria da história: uma teoria da história como ciência (RÜSEN,2015, p. 11), expõe de maneira sintética e clara o ponto fundamental a ser investigado

${ }^{3}$ Historiador e filósofo nas áreas de teoria e metodologia da história, história da historiografia e da metodologia do ensino de história. 
e discutido. No campo da educação histórica, o objetivo é conferir se livros literários, músicas, filmes e documentários brasileiros, enquanto linguagens da cultura do século XVIII a XXI, problematizam os temas relativos ao ensino da história e da cultura afro-brasileira e indígena.

\section{Lei $n^{0}$. 10.639/03 e lei $n^{0} 11.645 / 08$ - desafios de uma aprendizagem significativa no ensino superior}

$\mathrm{Na}$ esperança de uma ruptura eurocêntrica, excludente e racista, surgem leis como as de $\mathrm{n}^{\mathrm{o}}$. 10.639/03 e $\mathrm{n}^{\mathrm{o}} 11.645 / 08$, que, em conta-gotas, são implantadas em diversos segmentos educacionais, dentre eles o ensino superior, foco desta pesquisa.

Ao adentrar a sala de aula, sob o olhar questionador do público alvo pertencente à área da tecnologia, numa grade curricular específica e distante das ciências humanas, surge a questão: por que estudar história e, principalmente, história e cultura afro-brasileira, além disso acoplada à indígena? Indagações que despertaram o início de um caminho apaixonante por novas técnicas. Cabe evidenciar, como pressuposto às eventuais questões levantadas pelo porquê, que a história foi e tem sido um enfrentamento entre o passado e o presente, num conflito tão atual dos obstáculos sociais, econômicos e jurídicos enfrentados pelo Movimento Negro - do período escravagista ao hodierno preconceito e desigualdade social -, e em relação ao indígena, que luta pela conservação e delimitação das coisas lhes são próprias (tradições, cultura e terras) e reconhecidas pela Constituição do país.

Definida a conjuntura, inicia-se a proposta de um ensino de História e Cultura AfroBrasileira e Indígena de acordo com a perspectiva de Rüsen, ou seja, não somente a partir dos direcionamentos do parecer do Conselho Nacional de Educação - CNE/CP 3/2004 -, mas na particularidade de que o conhecimento metódico do passado, dos processos de dominação, apropriação, resistência, alimenta o agir prático e cotidiano e, portanto, o impulso à constituição da consciência histórica de acadêmicos/as da graduação. Além disso, ajuda a reformulá-la e a proporcionar novas identidades, pertencimentos e alteridades, o que estabeleceria, na contramão do pensamento contemporâneo social brasileiro, um cenário propício a uma pedagogia antirracista e respeitosa das etnias por quanto diz respeito aos direitos humanos.

A intenção foi traçar um programa de investigação de acordo com o prisma do autor citado, que requer que se compreenda a dimensão de modernidade. Rüsen (1997, p. 82) explica que o homem desenvolveu "a capacidade de organizar a vida humana conforme conhecimentos e descobertas devidos à racionalidade e à pesquisa científica". Alerta que estamos "perdendo progressivamente as fontes do sentido e da significância de nossa própria vida" (RÜSEN, 1997, p. 82). 
Ainda segundo o autor, ocorre um "fenômeno oposto", que é o da perda progressiva de sentido e significado relacionados à "vida cultural", que é o inadiável requisito para se investigar e analisar estes campos com o propósito precípuo de contribuir para uma consciência constitutiva, considerando a ideia do nosso/a acadêmico/a e o modo de se relacionar com o passado. Esta consciência, em vias de aplicabilidade, contextualizada com a proposta desta pesquisa, consiste, nas palavras de Schmidt (2011, p. 109), na "aprendizagem no contexto universitário", "envolvendo sujeitos e contextos históricos e culturais".

Se a consciência constitutiva é desafiadora no campo da Didática da História preocupação da ciência da História -, é objetivo desta pesquisa estabelecer um diálogo com o pensamento rüseniano, que é o de recorrer ao passado e, analisando-o nas fontes propostas, encontrar o meio mais indicado para a interpretação do momento presente, com o intuito de agir num futuro.

\section{Consciência histórica, história e cultura afro-brasileira e indígena num diálogo intertextual}

A árdua tarefa do professor, em sala de aula, é de "criar situações de ensino para os alunos estabelecerem relações entre o presente e o passado", como orientam os PCNs (1998, p. 77), e entrelaçar presente e passado. Rüsen (2010a, p. 101) situa a "competência cognitiva ${ }^{4}$ na perspectiva temporal da vida prática, da relação de cada sujeito consigo mesmo e do contexto comunicativo com os demais". No movimento por ele proposto (2010a, p. 107), apropriar-se da história do próprio presente "exige do sujeito [...] que passe de uma a outra experiência". Esta etapa da pesquisa propôs-se, intencionalmente, passar por esta experiência, por intermédio dos recursos expostos, num processo dialético de interiorização de novas experiências acerca do passado, acreditando que com isso o sujeito conseguirá evoluir no tempo presente.

Além de responder às indagações introdutórias desta pesquisa, busca-se reinventar formas ou funções de se completar o saber histórico, intermediado por linguagens essencialmente culturais, como filmes e documentários brasileiros, livros literários e músicas brasileiras - linguagens que se consideram contribuições fundamentais para entrelaçar presente e passado. Por tal processo, o saber histórico é assegurado tanto pela educação histórica fundamentada nos princípios do pensamento da teoria da consciência histórica de Jörn Rüsen e da teoria da consciência crítica de Paulo Freire -, quanto pelas estratégias que descreveremos.

\footnotetext{
${ }^{4}$ Por competência cognitiva compreende-se competência narrativa.
} 


\subsection{Metodologia}

A pesquisa-ação, de natureza qualitativa, foi concluída com a primeira turma, de 49 acadêmicos/as, dos cursos superiores de Engenharia da Computação, Tecnologia em Desenvolvimento de Sistemas e Tecnologia em Desenvolvimento de Jogos Digitais da cidade de Araçatuba/São Paulo. A faculdade tem cerca de 4.500 alunos; a escolha do campo de investigação e da população recaiu sobre os que têm a disciplina História e Cultura AfroBrasileira e Indígena nos cursos de tecnologia. O instrumento foi aplicado pela professora da disciplina, cabe ressaltar que foi desenvolvida no ano de 2018, e apresentaremos gráficos, especificando dados nos resultados e discussões.

O estudo metodológico baseia-se em Thiollent (2004), para quem a perspectiva argumentativa da pesquisa-ação propõe o envolvimento, no caso desta pesquisa, da pesquisadora-professora com os/as participantes-acadêmicos/as. A proposta, com indagaçõesargumentativas submetidas aos participantes, contempla a análise da consciência histórica prévia do/a acadêmico/a sob a óptica da competência narrativa da consciência histórica, com o que se pretende, consequentemente, extrair resultados das narrativas discursivas expostas e dos questionários aplicados. Cabe esclarecer que os questionários possuem dois momentos: antes de iniciar e depois de concluir as atividades intencionais, com o intuito de averiguar e interpretar os dados. Neste contexto, aplicaram-se duas questões, com as quais se pretendia dos discentes a descrição de "como observam a participação dos indígenas/negros e o significado das palavras índio 5 negro na história do Brasil”.

No decorrer do trabalho, são instrumentalizados trechos de livros literários, de músicas, documentários e filmes enquanto linguagens culturais e históricas. Em primeiro lugar, filmes e documentários, mais especificamente, os seguintes: 1 - "Vista Minha Pele" (2003), de Joel Zito Araújo; 2 - Terra Vermelha (2008), de Marcos Bechis; 3 - Quanto Vale Ou É Por Quilo? (2005), de Sergio Bianchi; 4 - À Sombra de Um Delírio Verde (2011), de An Baccaert, Cristiano Navarro, Nicola Um, resultando em dissertações dos alunos.

Em segundo lugar, leitura e análise de trechos de livros da literatura brasileira, num recorte histórico-literário do século XVIII a XXI. Para esse fim, optou-se por produções essencialmente brasileiras, julgadas pertinentes à temática da proposta, incluindo-se nesse rol: Iracema (1865), de José de Alencar; Macunaíma (1928), de Mário de Andrade; Maíra (1976),

\footnotetext{
${ }^{5}$ Lembrando que o intuito é debater a assertiva de Daniel Munduruku em entrevista: a "palavra 'indígena' diz muito mais a nosso respeito do que a palavra 'índio'. Indígena quer dizer originário, aquele que está ali antes dos outros", defende Munduruku. E outras discussões expostas em MUNDURUKANDO. Disponível em: http://danielmunduruku.blogspot.com.br. Acesso em 20/3/2018. E entrevista. In: Mekukradjá - Círculo de saberes 2018, organizado pelo Instituto Itaú Cultural. Daniel Munduruku 27 dez 2018. 6min. 08s. Disponível em: https://www.youtube.com/watch?v=4Qcw8HKFQ5E. Acesso em: 27 dez. 2018.
} 
de Darcy Ribeiro; A Majestade do Xingu (1997), de Moacyr Scliar; O Cortiço (1890), de Aluísio Azevedo; Pai Contra Mãe (1906), de Machado de Assis; Clara dos Anjos (1948), de Lima Barreto; Um Defeito de Cor (2006), de Ana Maria Gonçalves. Alguns trechos dos livros citados contribuíram para este diálogo, correlacionando a crise do presente com o passado. Assim foi que se optou pelo contexto de algumas personagens fictícias para se observar a representação e a participação do sujeito negro e, na sequência, a do povo indígena.

Quanto a presença do negro ${ }^{6}$, no século XXI, por meio das histórias que recheiam o livro Um defeito de cor, endossa a justificativa de Esméria, segundo a qual isso devia ser assim "para que não pegássemos de novo os vícios selvagens dos pretos, e assim servirmos melhor aos brancos" (2017, p. 80-81).

No século XX, Clara dos Anjos, de Lima Barreto, situa-se num cenário histórico pósabolição, em que "uma mulher preta e pobre no Rio de Janeiro", exposta à sedução de uns "valdevinos" de "boa" família, ouvira, ofendida, "os desaforos da mãe do seu algoz", que lhe dizia que ela "era muito menos no conceito de todos (BARRETO, 2017, p. 173).

Já no livro Pai contra mãe (1906), Machado de Assis (2007, p.13) relata, no conto ofícios e aparelhos e em "Candinho", fornece um quadro escravagista do Brasil do século XIX, num discurso conservador do "direito de propriedade" (palavras irônicas do autor), aos pretos que, por inaptidão, fogem, aplicar-se-á o “ofício de pegar escravos fugidos”.

Em O cortiço (1890), Aluísio Azevedo, no período do Segundo Império, nos apresenta o mundo da pobreza na moradia, em marcante descrição realista-naturalista de personagens negras estereotipadas: Rita Baiana, a "mulata" hiperssexualizada, e Bertoleza, a mulher retinta, animalizada, humilhada até no momento de sua morte, “[...] rugindo e esfocinhando moribunda numa lameira de sangue" (AZEVEDO, p.164).

Usar e reutilizar essas linguagens culturais nacionais confirma, ou não, nossas origens? Confirmam-se "na continuidade, na tradição e na intemporalidade", representando como primordial "a verdadeira natureza das coisas"? O 'acordamento' surge de uma sonolência no intuito de assumir sua existência, seu caráter nacional, como também no de apreender que a história desse povo não foi escrita por eles. Neste caso, o povo indígena, nesse período da história, não escreveu. No livro Majestade do Xingu, Moacyr Scliar expõe a visão sobre esse povo, escrevendo ter sido vítima "de sua própria afoiteza em meter-se, aventurosamente, por essas matas e aqui deixar-se prenhar (SCLIAR, 2009, p. 226).

\footnotetext{
${ }^{6}$ As manifestações aqui discutidas e mencionadas, foram resultado das discussões com as turmas em sala de aula e incorporadas simultaneamente com a descrição de cada livro mencionado.
} 
Mas em Maíra, Darcy Ribeiro, em base a estudos etnográficos, assim descreve a organização e as relações na aldeia dos mairuns: "Cada mairum, encontrando outro, sabe se ele é de cá ou de lá, se é fodível ou proibido, se é irmão ou cunhado (RIBEIRO, s/d, p. 47). Numa autorreflexão, a narrativa aponta os conflitos e questionamentos existenciais de Mairum: "Não sou soldado que regressa vitorioso ou derrotado. Não sou exilado que retorna com saudades da raiz. Sou o outro em busca do um. Sou o que resulto ser, ainda, nesta luta por refazer os caminhos que me desfizeram” (RIBEIRO, s/d, p. 79). O autor articula, de forma literária, elementos culturais nas narrativas subjetivas. Segundo reflexão de Bhabha (1998, p. 29), ele oferece um "espaço de intervenção que emerge dos interstícios culturais" que contribuem para a "invenção criativa dentro da existência".

No prefácio de Macunaíma (1928), Mário de Andrade expõe a tessitura do "herói sem nenhum caráter" (2016, p. 8), que, ao sair do banho, "estava branco louro e de olhos azuizinhos", tendo a água lavado "o pretume dele". Ninguém indicaria mais que era "um filho da tribo retinta dos Tapanhumas" (ANDRADE, 2016, p. 42).

Iracema (1865), de José de Alencar (2018, p. 9), segundo prefácio de Carlos Newton Júnior, teria contribuído "para certa revalorização do papel do índio na formação do povo brasileiro", enquanto "o negro ainda aguardaria a sua hora e vez". Ou seja, apropriem-se da história e observem quem tem vez! Alencar (2018, p.18) descreve romanticamente Iracema: “a virgem dos lábios de mel...”. E Martim, no encontro com Iracema, seria um guerreiro estranho “a contemplá-la” (ALENCAR, 2018, p. 19).

Nota-se, em Alencar, a aproximação cordial entre índios e brancos, num período de conciliação "velada" da historicidade, pois ainda assombrava o Segundo Reinado, que representava uma coesão de inúmeros interesses que ajudariam a entender que o fim da escravidão se deu em virtude da economia cafeeira no Centro-Sul de nosso país. E o povo indígena, nesta história? Segundo Holanda (2014), “cumpria apenas resolver o problema do trabalho. E verificou-se, frustradas as primeiras tentativas de emprego do braço indígena, que o recurso mais fácil estaria na introdução de escravos africanos" (HOLANDA, 2014, p. 55).

$\mathrm{Na}$ visão romantizada do branco da época, por uma consciência transitiva ingênua freireana da história, como também por uma consciência prévia rüseniana, sustentam Collet, Paladino e Russo (2014, p.18-19) que "esse índio idealizado, romântico, construído por livros, pela imprensa e por políticas governamentais, não está acabando. Ele nunca existiu! Os 
indígenas "de verdade" são muito diferentes dessa imagem". Por esta pontual alegação, esclarecem os autores a diversidade cultural ou até mesmo as diferenças ligadas à colonização ${ }^{7}$.

Num segundo momento, considera-se, nas narrativas dos trechos dos livros citados, a manifestação da sociedade da época, repleta de dados históricos. A partir da análise de seu conteúdo, o/a acadêmico/a irá interpretar com olhar investigativo tais dados. Nas palavras de Mia Couto (2013, p. 29), a história de "um homem é sempre mal contada". A pessoa, para o autor, é nascente e não "segue uma única vida; todos se multiplicam em diversos e transmutáveis homens". O homem inevitavelmente fora subdividido, segregado e incontestavelmente cruel em seus posicionamentos abjetos, Couto nos traz a reflexão de que a pessoa é uma humanidade. Por conseguinte, as estratégias aqui descritas são significativamente pensadas na humanização do sujeito em respeito às especificidades de cada um. O/a acadêmico/a necessita compreender quem é o negro antes de ser o negro marcado pelo estereótipo escravagista que o rodeia; e o índio não é um selvagem à beira de domesticações, nem a sobra dos resquícios da colonização. Ambos são homens e mulheres pertencentes à sociedade brasileira, na redundância indispensável de apropriar-se de seres humanos, humanamente humanos.

Enfim, como última etapa, a leitura, a análise e a correlação entre filmes e documentários anteriormente assistidos, com o recorte histórico-literário do século XVIII a XXI e as músicas brasileiras: Haiti, de Caetano Veloso e Gilberto Gil; Música Carne, de Elza Soares; Um Índio, de Caetano; Nozani Na, de Heitor Villa Lobos, interpretado por Milton Nascimento e Marlui Nóbrega Miranda, seguido propostas dissertativas.

A segunda aplicação do questionário ocorreu no final do mês de novembro seguida da análise das respostas, extraídas das dissertações e participações ativas dos sujeitos envolvidos, buscando a "intervenção com mudanças dentro da situação investigada" (THIOLLENT apud BRANDÃO, 1999, p. 83-84). As atividades desafiaram a relação das linguagens culturais e o ensino de história, num processo emancipatório de criticidade dos/as acadêmicos/as. Sob a luz de Rüsen (2010b), sentidos novos podem levar a novas representações no contexto histórico da experiência do passado, que requer novas técnicas, que se encontram neste estudo.

\footnotetext{
${ }^{7}$ Os autores expostos neste estudo fizeram parte das discussões, principalmente quando a professora propunha uma indagação, perpassava por eles para ampliar o conhecimento sobre as temáticas propostas.
} 


\subsection{Resultados e discussões}

O exercício da apropriação da história é meta nesta pesquisa para, na expressão de Rüsen (2010a, p. 107), “assenhorear-se de si a partir dela", para uma apropriação "mais ou menos consciente dessa história". Nesta perspectiva, "a pesquisa-ação é sobretudo ligada à visão emancipatória" (THIOLLENT apud BRANDÃO, 1999, p. 84). O intuito é promover essa (des)colonização de pensamentos e discursos densamente racistas e escravagistas. Pertinentemente, Apple (2017, p. 48) discursa sobre a instrução crítica (que ele chamava de conscientização) de traços freireanos, visto que Freire (1981, p. 17) se refere à conscientização como algo que "permite ao homem transformar a realidade", pois, "na medida em que os homens, dentro de uma sociedade, vão respondendo aos desafios do mundo, vão temporalizando os espaços geográficos" e "fazendo história pela própria atividade criadora" (FREIRE, 1981, p. 17). Na primeira aplicação das questões, ocorreram as manifestações que apresentaremos de forma sucinta nos gráficos a seguir. Assim é que uma "leitura crítica do mundo se funda numa prática educativa crescentemente desocultadora de verdades. Verdades cuja ocultação interessa às classes dominantes da sociedade (FREIRE, 2001, p. 11).

Nota-se, na primeira aplicação do questionário (gráficos 1 e 2), a imagem pejorativa, discriminatória e excludente relacionada ao negro.

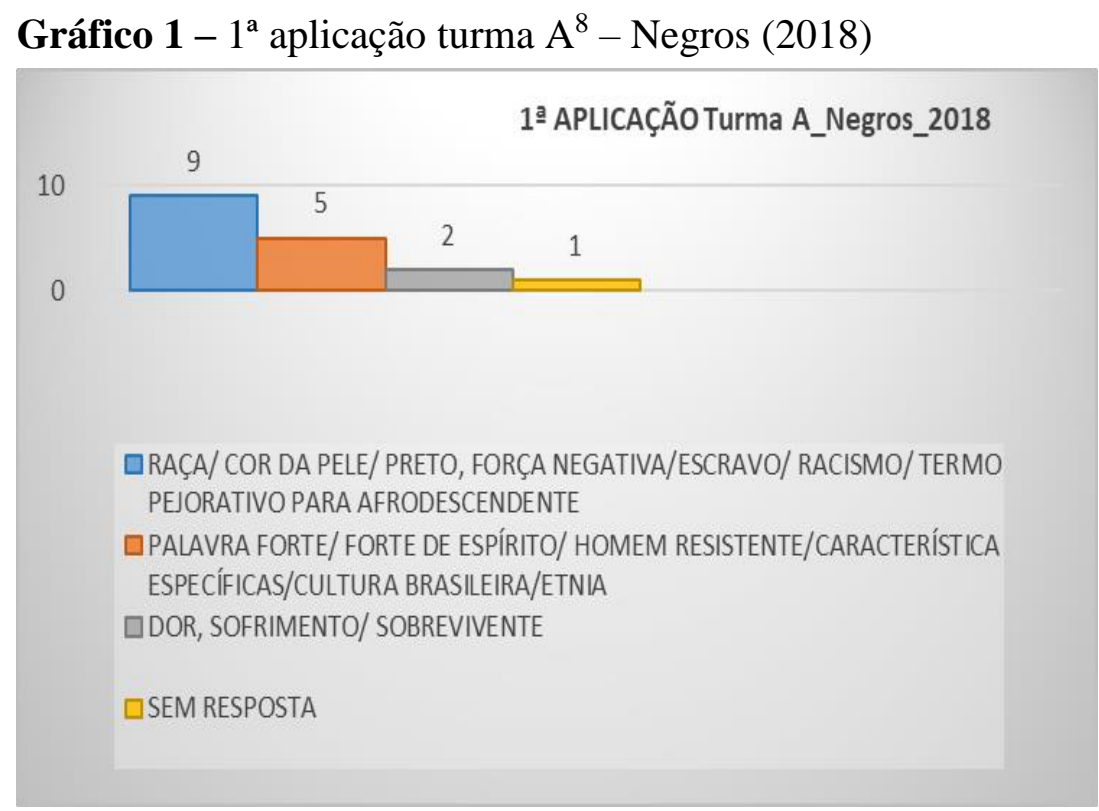

Fonte: Autores.

\footnotetext{
${ }^{8}$ Lembrando que, na Turma A corresponde a uma junção de dois cursos (1- Tecnologia em Desenvolvimento de Jogos Digitais e 2- Tecnologia em Desenvolvimento de Sistemas) que assistiam juntos a disciplina.
} 


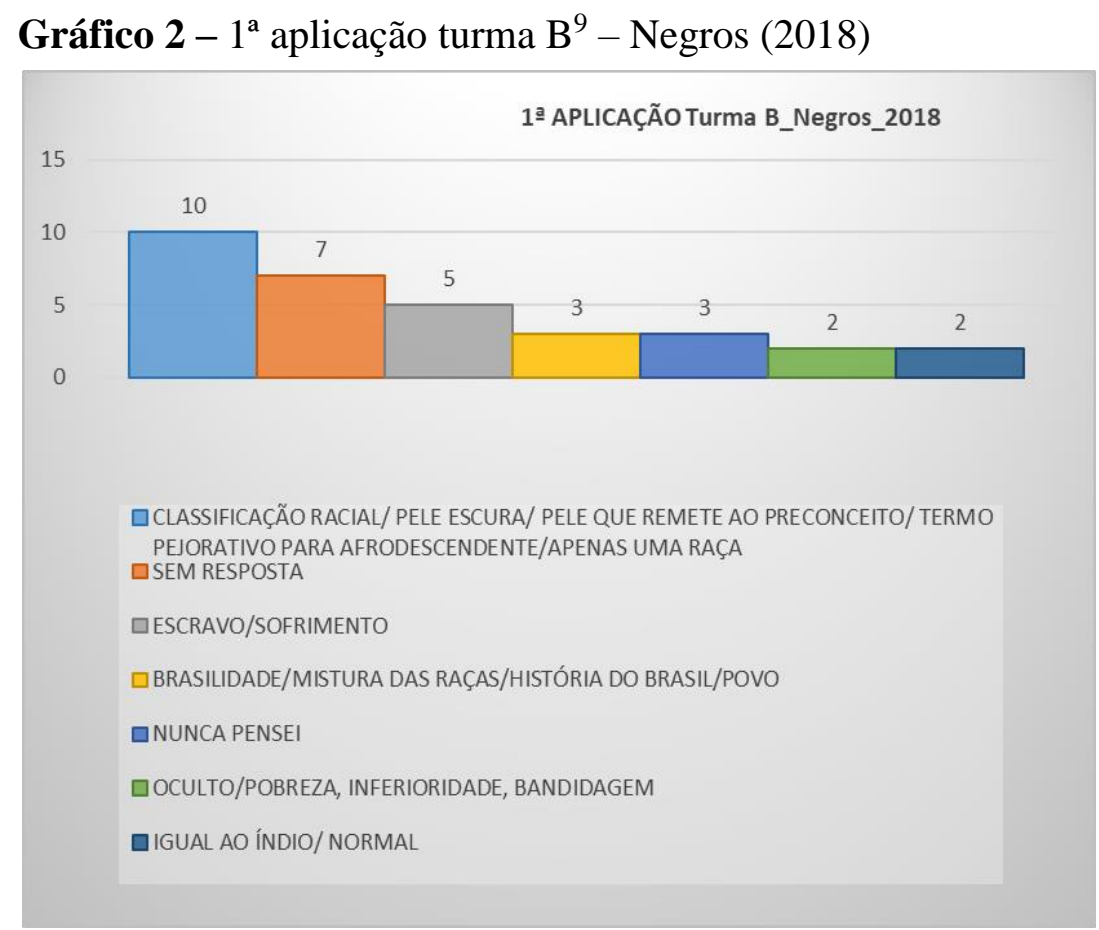

Fonte: Autores.

Observe que tanto no gráfico 1 quanto no gráfico 2, as terminologias relacionadas aos povos demonstram uma visão de apagamento histórico, e de segregação.

Em relação à turma TA e TB, há uma diferença pontual da quantidade de quem não respondeu: TA, 1 acadêmico/a; TB, 7 acadêmicos/as. Outro aspecto refere-se à TB: 3 acadêmicos/as nunca pensaram a respeito. $\mathrm{O}$ pertencimento de histórico é mais expressivo na TA que na TB; na TB é nítido o posicionamento excludente do negro.

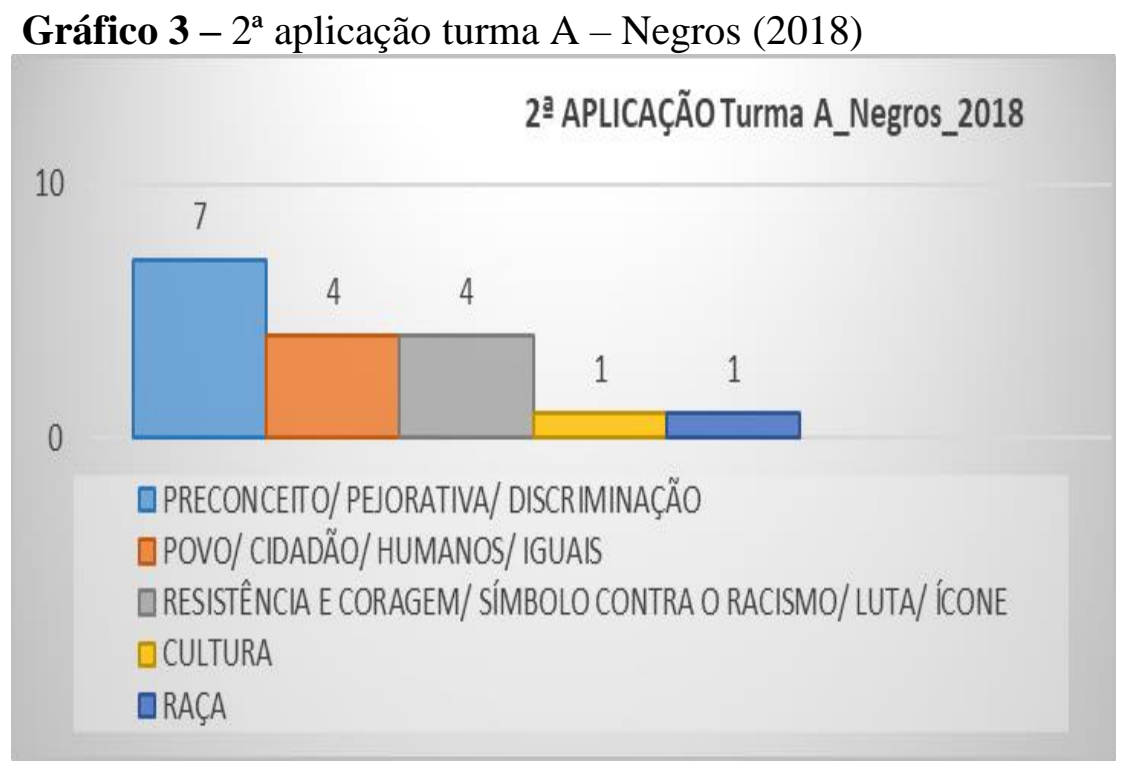

Fonte: Autores. 
Gráfico 4 - 2a aplicação turma B - Negros (2018)

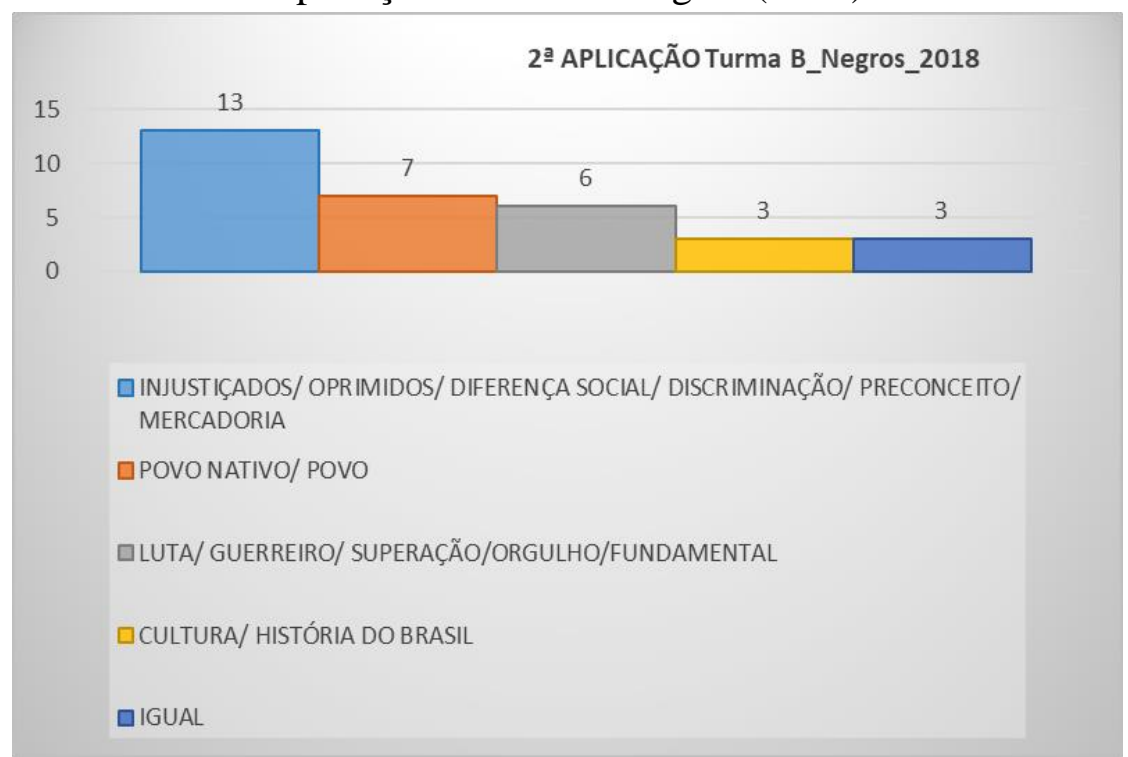

Fonte: Autores.

Esta aplicação traz à luz da reflexão o processo proposto, destacando alguns aspectos após as discussões e programação de estudo e pesquisa: tanto a TA como a TB se dão conta do preconceito enfrentado pelo negro. Na TA, 7 acadêmicos/as, e na TB, 13 acadêmicos/as. Observe-se a inserção representativa do significado na TA: povo, cidadão, humano, iguais, resistência e coragem, povo, luta, ícone, cultura. E na TB: luta, guerreiro, superação, orgulho, fundamental, cultura história do Brasil, e igual que constam nos gráficos 3 e 4.

A seguir observe as respostas correlacionadas aos povos indígenas:

Gráfico 5 - $1^{\mathrm{a}}$ aplicação turma A - Povos indígenas (2018)

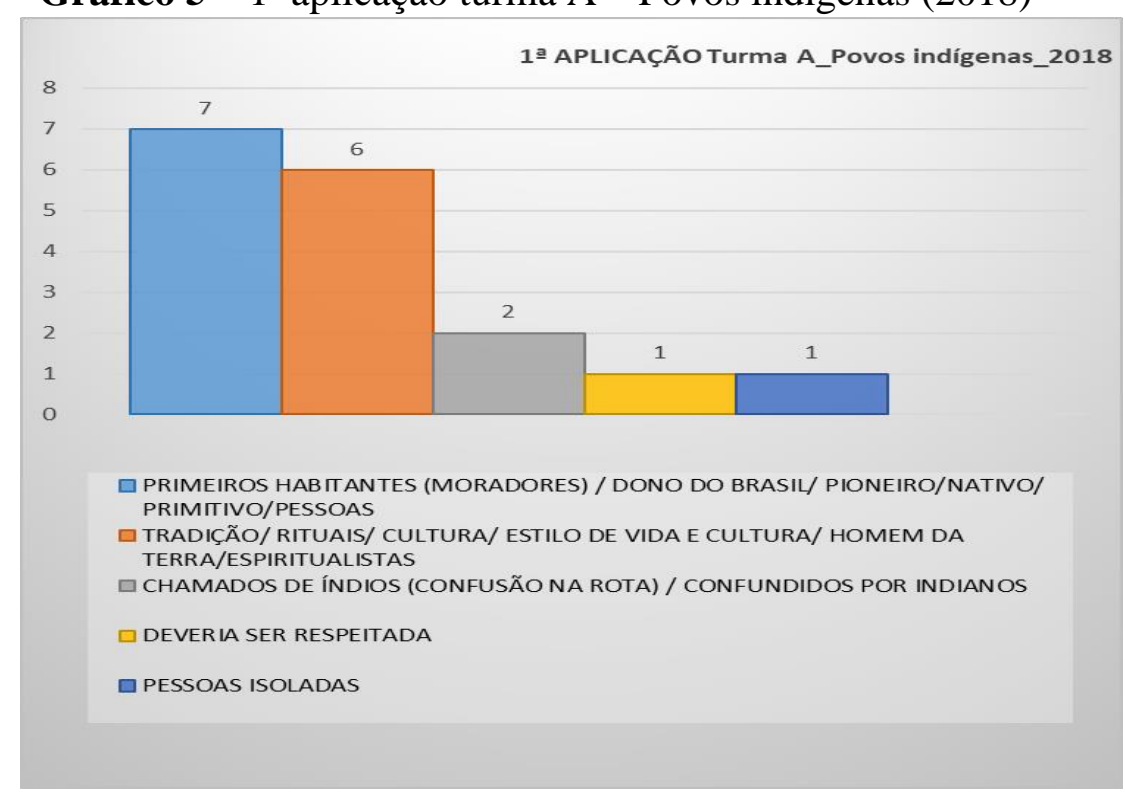

Fonte: Autores. 
Gráfico 6 - $1^{\text {a }}$ aplicação turma B - Povos indígenas (2018)

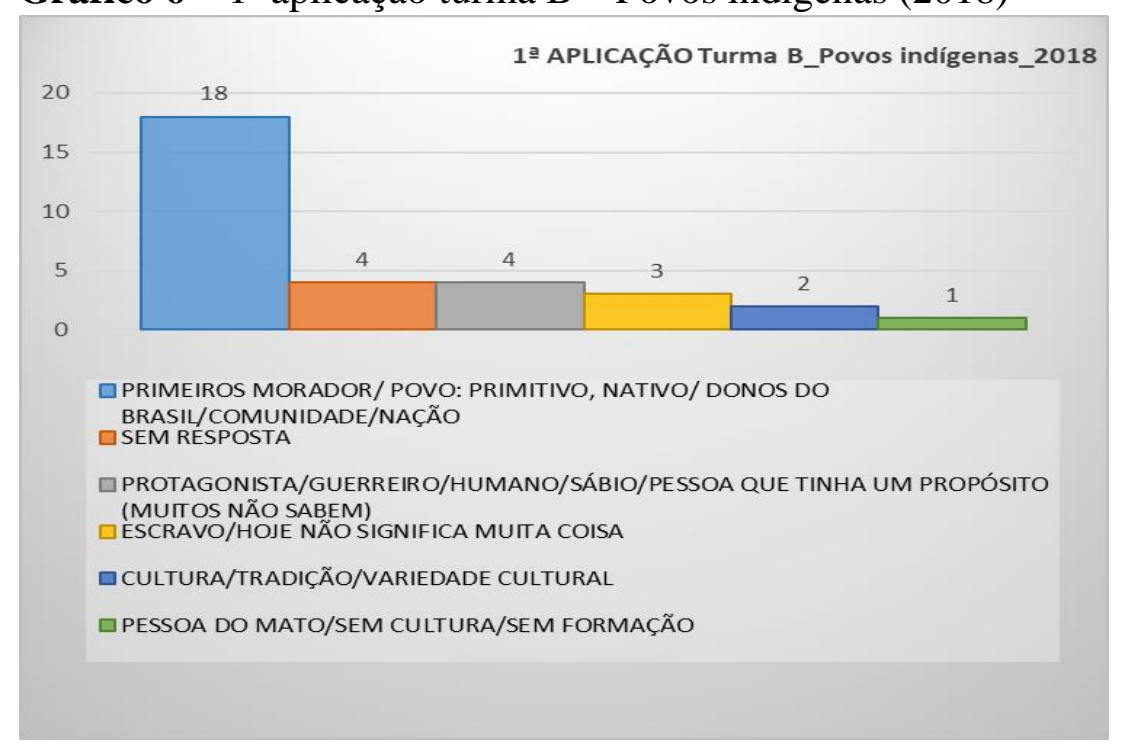

Fonte: Autores.

Já a do índio, hoje, "não significa muita coisa", na fala de um/uma acadêmico/a da TB na primeira aplicação, tanto em sua visão estereotipada quanto em sua concepção de insignificância dos sujeitos em questão; 4 acadêmicos/as da mesma turma não responderam. Isoladamente, e de forma unitária, manifesta-se, tanto na TA quanto na $\mathrm{TB}$, a imagem significativa dos sujeitos como: respeito, nação, protagonista e pessoas.

Nas primeiras aplicações às Turmas A e B, cabe evidenciar a dificuldade, prevista por Hall (2006, p.10), de perceber uma identidade nacional contra uma "crise de identidade", presente na mudança estrutural de nossa sociedade moderna no "final do século XX".

O autor (2006, p. 10) explica que isso "está fragmentando as paisagens culturais de classe, gênero, sexualidade, etnia, raça e nacionalidade, que, no passado, nos tinham fornecido sólidas localizações como indivíduos sociais", abalando, infelizmente, "a ideia que temos de nós próprios como sujeitos integrados" (HALL, 2006, p. 10).

Nesse contexto de incertezas manifestadas nas narrativas discentes, cabe discutir o sujeito pós-moderno que, nas palavras de Hall (2006, p. 11), "não tem identidade fixa, essencial ou permanente" para interpretar a problemática apresentada, ou seja, o significado do índio e do negro para os/as acadêmicos/as. O sujeito pós-moderno, público desta pesquisa, em crise identitária, privilegia, em determinadas narrativas, em detrimento de outras, a relação de poder e domínio. No início do processo desta pesquisa, para um discente da Turma B, o termo "negro" sugere "pobreza, inferioridade e bandidagem".

$\mathrm{Na}$ segunda aplicação, representado nos gráficos 7 e 8, 11 acadêmicos/as da TA manifestam a assertiva de tradição, cultura, origem e símbolo. Na TB, 14 acadêmicos/as 
enfatizam donos da terra, verdadeiros brasileiros, nativo, origem e raízes, entre outros significados expressados. É nesta turma que se manifestam, em 5, a dor, a minoria, a injustiça, a discriminação, o sofrimento e as consequências da colonização.

A manifestação, até então isolada e dispersa, torna-se presente nas respostas às questões, como também nas dissertações, como por exemplo, na TA, quando um dos alunos afirma que os índios são chamados pelos brancos de "ladrões de terras". Demonstrados nos gráficos 7 e 8 a seguir:

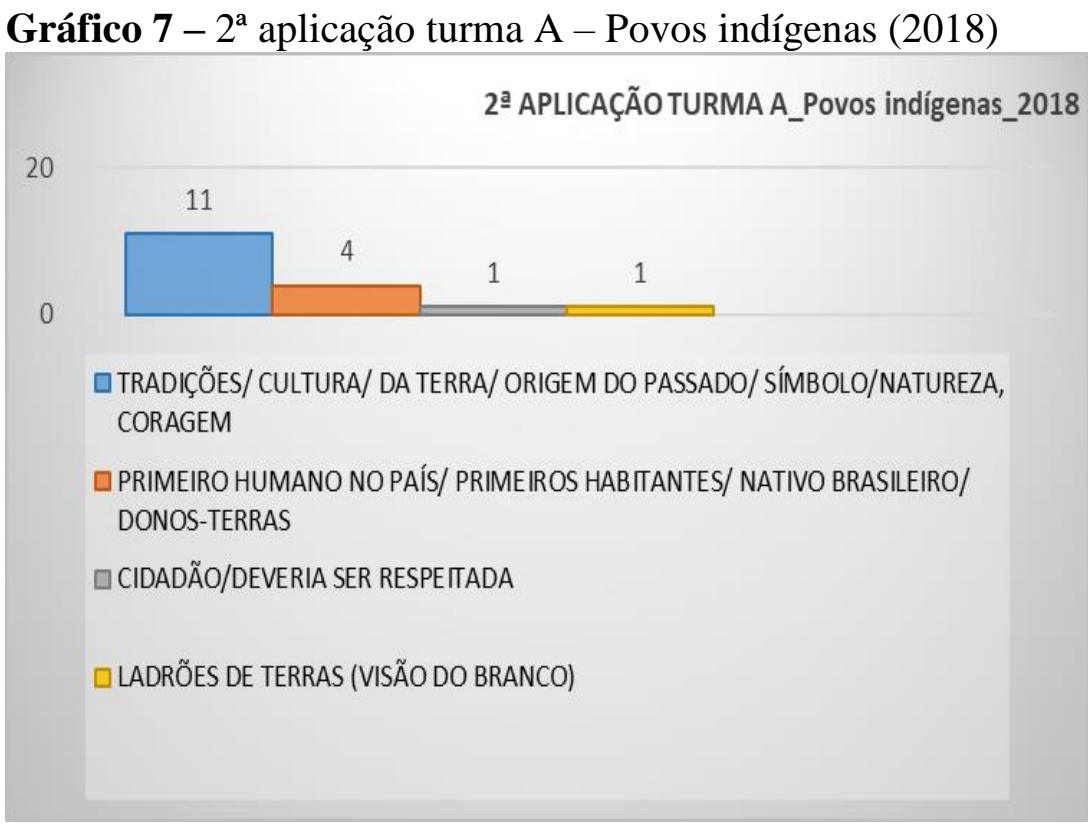

Fonte: Autores.

Gráfico 8 - 2 a aplicação turma B - Povos indígenas (2018)

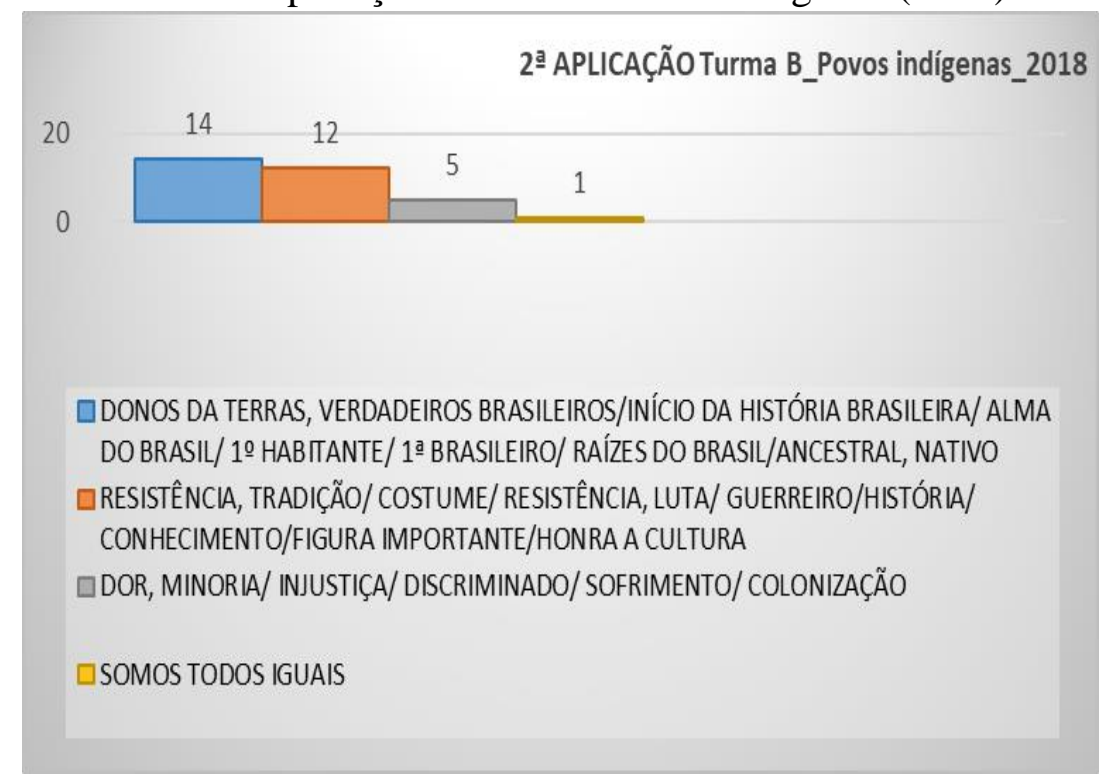

Fonte: Autores. 
"Da curiosidade ingênua que caracterizava a leitura pouco rigorosa do mundo à curiosidade exigente, metodizada com rigor, que procura achados com maior exatidão" (FREIRE, 2001, p. 15). Nessa consciência e mundo, o autor (2001, p. 16) afirma "não poder ser entendidos separadamente", principalmente ao nos referir às relações contraditórias entre as leis e sua aplicabilidade em sala, como nos trechos das dissertações dos alunos. Nas palavras dos/as acadêmicos/as: A $1{ }^{10}$ descreve que - o problema é que "deveria ser tratado de forma mais intensa nas escolas", de modo que assim "as pessoas aprendam a respeitar uma as outras". O A2 diz que "falta o mínimo de respeito com a cultura". O A3 considera um "terrível cenário de abuso, preconceito e invasão por parte da elite colonizadora”. E, finalizando, na perspectiva freiriana, o A 4 declara: "Devemos ter uma conscientização maior sobre o tema e o que ocorre no Brasil"! Assim, os resultados confirmam o caminho traçado, o da utilização de linguagens culturais e históricas no processo de ensino e aprendizagem das aulas de História e Cultura Afro-Brasileira e Indígena. De fato, o problema não estava tanto em se recuperar as "heranças do passado", mas, sim, em se (re)pensar o que se deveria fazer no "presente" (ROIZ, 2018, p. 231).

Os instrumentos impulsionaram a construção do pensamento histórico e da aprendizagem histórica e, por conseguinte, para o incremento da consciência histórica e a superação de algumas dificuldades dos sujeitos envolvidos nesta pesquisa.

\section{Considerações finais}

O grande desafio desta pesquisa foi a desconstrução dos discursos apresentados pelos/as acadêmicos/as dos cursos superiores em tecnologia, na disciplina de História e Cultura AfroBrasileira e Indígena ${ }^{11}$ - sobre a compreensão do significado das palavras índio e negro, e suas respectivas participações históricas, repensando passado, presente e futuro e os possíveis desdobramentos dos processos históricos.

Os livros brasileiros utilizados foram fundamentais para a análise do discurso colonial, eurocêntrico e patriarcal, num sistema de domínio sobre o outro - a visão do indígena, como "bárbaro" a ser domesticado, e o negro, segregado e submisso a coisificação - objeto de compra e venda (a carne mais barata numa imagem que se perpetuaria do século XVIII até o XXI) -, perspectiva estudada paralelamente ao conteúdo programático.

\footnotetext{
${ }^{10} \mathrm{~A} 1,2,3$ e 4 - se referem a trechos das dissertações de alguns alunos, para exemplificar o resultado das discussões.

${ }^{11}$ As primeiras turmas A e B foram finalizadas em 2018; a próxima turma ocorreu no primeiro semestre de 2019, com outras turmas C e D
} 
Assim, permeando a conscientização na perspectiva freireana e na formação da consciência histórica rüseniana, as linguagens culturais (livros literários, músicas, filmes e documentários brasileiros) se justificam, com relevância, por expressarem a construção de uma identidade numa preocupação formal apoiada pela cientificidade investigativa do presente estudo.

A proposta, apresentada com indagações-argumentativas entre pesquisadora-professora e participantes-acadêmicos/as, contribuiu para instigar os sujeitos das duas primeiras turmas finalizadas - A e B - em 2018, em tempos difíceis de crise econômica, histórica, cultural e educacional.

É insurgente contar a história dos povos pelos povos, não somente os relatos de sofrimento diante das chibatas na clausura desumana das senzalas, mas a história de seus feitos, suas glórias, sua ascensão na sociedade, a cultura, os saberes ancestrais nesta diversidade intercultural que os povos nos presenteiam e infelizmente, por muito tempo foi silenciada. Ressalta-se a importância de entrelaçar presente e passado se assegurando o saber histórico em sua cientificidade experimental e curricular, atrelado à teoria da consciência histórica de Jörn Rüsen e à teoria da consciência crítica de Paulo Freire.

A prática pedagógica requer transformações dialogais que contribuam substancialmente na relação acadêmico/a e docente, exigindo novas representações, novas técnicas e o comprometimento ético, por todos/as os/as envolvidos/as nesse processo significativo de apropriação histórica.

\section{Referências}

ALENCAR, José de. Iracema. Rio de Janeiro: BestBolso, 2018.

ANDRADE, Mário de. Macunaíma. São Paulo: Martin Claret, 2016.

APPLE, Michael W. A educação pode mudar a sociedade. Petrópolis: Vozes, 2017.

ASSIS, Machado de. Pai contra mãe. Porto Alegre: Artes e Ofícios Editora Ltda, 2007.

AZEVEDO, Aluísio. O cortiço. São Paulo: Objetivo, Ano: s/d.

BARRETO, Lima. Clara dos Anjos. Belo Horizonte: Autêntica, 2017.

BHABHA, Homi K. O local da cultura. Belo Horizonte: Ed. UFMG, 1998.

BRASIL. Lei $n^{o}$. 10.639 de 9 de janeiro de 2003. Altera a Lei $\mathrm{n}^{\circ}$ 9.394, de 20 de dezembro de 1996, que estabelece as diretrizes e bases da educação nacional. Brasília, 2003. Disponível em: http://www.planalto.gov.br/ccivil_03/leis/2003/L10.639.htm. Acesso em: 30 ago. 2018. 
BRASIL. Lei $n^{\circ}$. 11.645, de 10 março de 2008. Altera a Lei no 9.394, de 20 de dezembro de 1996, modificada pela Lei $\mathrm{n}^{\circ} 10.639$, de 9 de janeiro de 2003, que estabelece as diretrizes e bases da educação nacional, para incluir no currículo oficial da rede de ensino a obrigatoriedade da temática "História e Cultura Afro-Brasileira e Indígena". Brasília, 2008. Disponível em: http://www.planalto.gov.br/ccivil_03/_ato2007-2010/2008/lei/111645.htm. Acesso em: 4 set. 2018.

BRASIL. Conselho Nacional de Educação (CNE). Resolução do Conselho Nacional de Educação - Câmara Plena (CNE/CP) no 01, de 17 de junho de 2004. Institui as Diretrizes Curriculares Nacionais para a Educação das Relações Étnico-Raciais e para o Ensino de História e Cultura Afro-Brasileira e Africana. Disponível em:

http://portal.mec.gov.br/cne/arquivos/pdf/003.pdf. Acesso em: 30 ago. 2018.

COUTO, Mia. Cada homem é uma raça. São Paulo: Companhia das Letras, 2013.

FREIRE, Paulo. Educação e mudança. Rio Janeiro: Paz e Terra, 1981.

FREIRE, Paulo. Pedagogia da indignação. São Paulo: Editora UNESP, 2000.

FREIRE, Paulo. Política e educação: ensaios. São Paulo: Cortez, 2001.

GONÇALVES, Ana Maria. Um defeito de cor. Rio de Janeiro: Record, 2017.

HALL, Stuart. A identidade cultural na pós-modernidade. Rio de Janeiro: DP\&A, 2006.

ROIZ, Diogo da Silva. A batalha pelo uso da "temporalidade": projetos de escrita da história para pensar o Brasil entre os "homens de letras" de São Paulo no início da década de 1930. In: ROIZ, Diogo da Silva; GOMES, Geovane Ferreira; SANTANA, Israel José (Org.). Direitos Humanos e o Pensamento Social Brasileiro. 1. ed. Serra: Editora Milfontes, 2018. 280p.

RÜSEN, Jörn. A História entre a Modernidade e a Pós-modernidade. História: questões e debates, Curitiba, v. 14, n. 26/27, p. 80-101, jan./dez. 1997.

RÜSEN, Jörn. História viva - Teoria da história III: forma e funções do conhecimento histórico. Trad. Estevão de Rezende Martins. Brasília: UnB, 1. reimp. 2010a.

RÜSEN, Jörn. Razão histórica - Teoria da história: os fundamentos da ciência histórica. Tradução: Estevão C. de Rezende Martins. Brasília: Editora Universidade de Brasília, 2010b.

RÜSEN, Jörn. Jörn Rüsen e o ensino de história. (Org.). SCHMIDT, Maria Auxiliadora; BARCA, Isabel; MARTINS, Estevão de Rezende. Curitiba: Ed. UFPR, 2011.

RÜSEN, Jörn. Teoria da história: uma teoria da história como ciência. Tradução: Estevão C. de Rezende Martins. Curitiba: Editora UFPR, 2015.

SCHMIDT, Maria Auxiliadora Moreira dos Santos. Hipóteses ontogenéticas relativas à consciência moral: possibilidades em consciência histórica de jovens brasileiros. Educar em Revista, Curitiba, Brasil, n. 42, p. 107-125, out./dez. 2011. Editora UFPR. Disponível em: http://revistas.ufpr.br/educar/article/view/25887/17278. Acesso em: 24 set. 2018. 
SCLIAR, Moacyr. A majestade do Xingu. São Paulo: Companhia das Letras, 2009. 